\title{
LA MUJER INDÍGENA Y SU DERECHO A LA PARTICIPACIÓN POLÍTICA EN MÉXICO*
}

\section{Jean Cadet Odimba On'Etambalako Wetshokonda**}

Fecha de recepción: 25 de abril de 2016

Fecha de evaluación: 14 de marzo de 2017

Fecha de aprobación: 16 de mayo de 2017

Artículo de reflexión

DOI: http://dx.doi.org/10.18359/prole.3046

Forma de citación: Odimba, J. (2017). La mujer indígena y su derecho a la participación política en México. Revista Prolegómenos Derechos y Valores, 20, 40, 145-158. DOI: http://dx.doi.org/10.18359/prole.3046

\section{Resumen}

Las diferentes culturas y subculturas pueden y deben coexistir y la tarea del Estado es conservarlas. En ese sentido, en México, uno de los temas que más se abordan es la participación política de la mujer indígena, el cual hace necesario su tratamiento, con fundamento en la prevalencia de dos ejemplos clásicos de desigualdad que analizaremos de forma conjunta en el presente artículo: la desigualdad de género y la desigualdad de los pueblos.

\section{Palabras clave:}

Derecho, mujer, indígena, participación política.

El presente trabajo es resultado del proyecto de investigación "Desarrollo de instrumentos elementales para capacitación en materia de equidad de género en los pueblos y comunidades indígenas", aprobado por la Coordinación de Investigación Científica de la Universidad Michoacana de San Nicolás de Hidalgo (Michoacán, México).

* Profesor investigador titular $\mathrm{C}$ de tiempo completo con carácter definitivo de la Facultad de Derecho y Ciencias Sociales de la Universidad Michoacana de San Nicolás de Hidalgo (Michoacán, México). Profesor de la División de Estudios de Posgrado en Derecho del Centro de Estudios de Humanidades y Ciencias Sociales de la Universidad de Guadalajara (Guadalajara, México) y profesor de cátedra en el Instituto de Formación e Investigaciones Jurídicas de Michoacán (Michoacán, México). Además, es docente invitado de la Universidad Autónoma de Chihuahua (Chihuahua, México) y miembro del profesorado del Instituto de Estudios Jurídicos de Jalisco (Jalisco, México). Premio Estatal al Mérito en Derechos Humanos 2013, miembro del Sistema Nacional de Investigadores Nivel Uno, autor de múltiples publicaciones en temas jurídicos entre los cuales se cuentan libros, capítulos de libros y artículos en revistas indexadas nacionales e internacionales. Correo electrónico: odimba@umch.mx 


\title{
THE INDIGENOUS WOMEN AND THEIR RIGHT FOR POLITICAL PARTICIPATION IN MEXICO
}

\begin{abstract}
Summary
Different cultures and subcultures can and should coexist. The task of the state is to preserve them. In this regard, in Mexico, one of the topics that is mostly addressed is the political participation of indigenous women, which makes it necessary to analyze by using as a foundation the prevalence of two classic examples of inequality which are discussed jointly in this essay: gender inequality and inequality towards the common people.
\end{abstract}

\section{Keywords:}

Law, women, indigenous women, political participation.

\section{A MULHER INDÍGENA E O SEU DIREITO À PARTICIPAÇÃO POLÍTICA NO MÉXICO}

\section{Resumo}

As diferentes culturas e subculturas podem e devem coexistir e a tarefa do Estado é conserválas. Nesse sentido, no México, um dos temas que são mais abordados, é a participação política da mulher indígena, o que exige seu tratamento, com base na prevalência de dois exemplos clássicos de desigualdade, que vamos analisar conjuntamente em este ensaio e são: a desigualdade de gênero e a desigualdade para os povos.

\section{Palavras-chave:}

Direito, mulher, indígena, participação política.

\section{Introducción}

El derecho tiene como finalidad proteger los valores de la igualdad y la justicia para el bien común, pero también enuncia las desigualdades $e$ injusticias que anteceden y dan origen a la necesidad de normas. De ahí que estas desigualdades se vean plasmadas en tipos y grados que hay que combatir.

Las situaciones de la problemática sociojurídica que se ponen en cuestión, nos han mostrado que las distintas culturas y subculturas pueden y deben coexistir y la tarea del Estado es conservarlas ${ }^{1}$. En México, uno de los temas que

1 Cada cultura comprende a su vez pequeños grupos o subculturas, que son unidades menores que pueden más se abordan, es la participación política de la mujer indígena, el cual hace primordial su tratamiento con fundamento en la prevalencia de dos ejemplos clásicos de desigualdad, que analizaremos de forma conjunta en el presente artículo y son los siguientes:

\footnotetext{
influenciar también de forma significativa el comportamiento de los individuos. La subcultura es pues un grupo cultural distinto que existe como un segmento claramente identificable dentro de una sociedad más compleja. Los miembros de una subcultura específica tienden a poseer creencias, valores y costumbres que los diferencia del resto, pero comparten con la mayoría las creencias culturales dominantes y los valores predominantes del comportamiento de una sociedad general.
} 


\section{A. La desigualdad de género}

La brecha de ingresos en México es una de las más altas en el mundo y más de la mitad de la población se encuentra en estado de pobreza. La coyuntura actual de las mujeres se caracteriza por la desigualdad en todos los ámbitos: ingresos, laboral, educativo, salud, familiar y político. Padecen las condiciones más desfavorables y asumen los mayores costos, algunos de ellos aceptados como "normales", ya que la transmisión de conocimientos y valores reproduce la ideología dominante.

La toma de conciencia de la discriminación que sufren las mujeres no es fácil en una sociedad donde son aparentemente libres y se requiere una gran capacidad para reconocer que es una ilusión la igualdad entre sexos. Por eso, a pesar de instaurarse como valor cultural el principio de la igualdad de género, la evidente subordinación femenina pasó a ser lo que se ha llamado la "opresión sin nombre". Según Nash (2004, p. 167) "las mujeres tuvieron incluso que aprender a identificar y nombrar su opresión".

\section{B. La desigualdad de los pueblos y comunidades indígenas}

Prevalece en estos grupos de personas el padecimiento de discriminación que en ocasiones no permite cubrir ni siquiera las necesidades básicas de subsistencia; viven en la pobreza, marginación, sin servicios públicos, etc.; lo que a su vez, repercute en sus derechos concernientes al desarrollo social y político, entre otras cosas.

La cuestión a tratar es cómo estas dos circunstancias de vulnerabilidad son los principales obstáculos para la participación política de la mujer indígena.

\section{Las mujeres indígenas y su derecho a la participación política}

Con regularidad pensamos que al indígena se le ha intentado reconocer jurídicamente como sujeto de derechos especiales solo en convenciones de la Organización de las Naciones Unidas, el primer antecedente interamericano lo encontramos en Pátzcuaro, Michoacán. Este recibió el nombre de Convención sobre el Instituto Indigenista Interamericano (1940). "Los indigenistas de Pátzcuaro tenían percepciones más amplias de los problemas de lo que se piensa. Hicieron énfasis tanto en temas de 'clase' como de 'cultura' y también se preocuparon por fomentar la participación de los mismos voceros indígenas" (Pineda, 2012, p. 17). Además contaron con la aportación de Lázaro Cárdenas, quien, como gobernador en aquel entonces, acentuó sobre la necesidad de sus derechos y sus tierras.

Referente a los derechos de la mujer indígena, uno de los puntos más importantes fue la necesidad de protegerla. Dicho documento no culminó con el verdadero reconocimiento y el respeto de sus derechos en el país, a pesar de ello fue uno de los primeros llamados a la sociedad para revalorizar el papel de los aborígenes y así lograr un precedente para la participación política de la mujer indígena.

Por otro lado y para entrar en las generalidades del sistema nacional, la participación política por muchos años no se conjugó con la participación electoral, si bien ambas van de la mano y son parte de los derechos políticos no significan lo mismo. Aun en la actualidad, se considera que el derecho electoral "se refiere al sufragio en cuanto a las condiciones para poder participar en las elecciones y a la configuración de este derecho de participación" (Larrosa, 2007, p. 206). Es decir, se percibe solamente como el derecho al voto, mientras que el derecho a la participación política abarca un mayor contexto que contiene:

1. El derecho a elegir libremente a los representantes populares.

2. El derecho a pertenecer libremente a un partido político o cualquier otro tipo de institución enunciada por las leyes electorales. 
3. El derecho de poder fungir como candidato para los puestos de elección popular.

4. El derecho de promover y ser partícipe de las políticas públicas que reflejen las necesidades fundamentales de la comunidad.

El ejercicio del voto de la mujer y su participación en cargos de elección popular, son de igual relevancia y por eso se ha determinado que los partidos deben registrar un mínimo de $50 \%$ de mujeres en su planilla ${ }^{2}$. No obstante, el problema es aún más complejo ya que los pueblos y comunidades indígenas tienen costumbres que nunca han encajado en el sistema político, de ahí que se les respete su cultura y se establezca el derecho a la libre autodeterminación de su gobierno.

México asumió el compromiso internacional de respetar a la población indígena, sus sistemas de elección y sus estructuras de cargos y organismos públicos, principalmente a través del artículo $1^{\circ}$ del Pacto Internacional de Derechos Civiles y Políticos ${ }^{3}$, el Tratado 169 de la Organización Internacional del Trabajo ${ }^{4}$ y la reforma al artículo $2^{\circ}$ constitucional $^{5}$.

2 Las últimas observaciones para garantizar la paridad se encuentran en INE/CG63/2016: "Acuerdo del Consejo General del Instituto Nacional Electoral por el que, en ejercicio de la facultad de atracción, se emiten criterios generales a efecto de garantizar el cumplimiento al principio de paridad de género en la postulación de candidaturas para todos los cargos de elección popular local".

3 "1. Todos los pueblos tienen el derecho de libre determinación. 2. En virtud de este derecho establecen libremente su condición política y proveen asimismo a su desarrollo económico, social y cultural" (Pacto Internacional de Derechos Civiles y Políticos, artículo $1^{\circ}$ ).

4 "Todos los pueblos tienen el derecho de libre determinación; en virtud de este derecho, determinan libremente su condición política y persiguen libremente su desarrollo económico, social y cultural" (Convenio 169 de la OIT, artículo $2^{\circ}$ ).

5 "Esta Constitución reconoce y garantiza el derecho de los pueblos y las comunidades indígenas a la libre determinación y, en consecuencia, a la autonomía [...]" (Constitución Política de los Estados Unidos Mexicanos, DOF, 14 de agosto de 2001, artículo $2^{\circ}$, A).
En lo que concierne a la igualdad de género en la participación política, el país firmó la Convención sobre los Derechos Políticos de la Mujer (1953): "deseando igualar la condición del hombre y de la mujer en el disfrute y ejercicio de los derechos políticos", con tres compromisos principales que hoy forman parte del discurso de la igualdad de las mujeres: ejercer el derecho al voto, ser elegibles y ocupar cargos públicos. Este compromiso se reafirmó en el artículo $7^{\text {o }}$ de la Convención sobre la eliminación de todas las formas de discriminación contra las mujeres (1979).

Entre las dificultades que implica la libre autodeterminación del gobierno en los pueblos y comunidades aborígenes está una afectación hacia las mujeres, ya que la mayoría de estos considera que la nativa no tiene porqué participar de forma plena, desde ejercer el voto hasta poder ocupar cargos de elección popular (Cámara de Diputados H. Congreso de la Unión LXIII Legislatura, 2014). Es evidente que esta situación constituye una discriminación de género y una violación a los derechos políticos de la mujer indígena, por lo cual, no permite que la cultura se sobreponga.

La búsqueda de igualdad para la participación política de la mujer indígena, ha sido mucho más difícil que la búsqueda de igualdad para la participación de la mujer en general. Legislar para que las mujeres tuvieran igualdad de oportunidades en la vida política del país fue una lucha que comenzó por el derecho al voto y llevó a invadir prejuicios de la cultura mexicana que incurrían en la discriminación. Hoy día se ve como algo normal, pero costó años de persistencia.

Sin embargo, en el caso de los pueblos y comunidades indígenas encontramos una tradición mucho más antigua y arraigada donde la mujer religiosamente debe obedecer a Dios pero también al hombre (López y Pitarch, 2006); en los movimientos revolucionarios no se le ve como el género débil, pero a la hora de establecer derechos no se le reconocen igualdad de condiciones (Pequeño, 2009). La mujer indígena trabaja en 
la agricultura mucho más que el hombre, pero su esfuerzo no es considerado tan ejemplar como el de este (FAO, 2004); políticamente, en especial en los cargos de liderazgo, se sigue eligiendo más al hombre porque todas las estructuras sociales indican que es primero él, en particular si se trata de comunidades indígenas machistas (Becerra y Mendoza, 2007).

Por otro lado, las tradiciones de desigualdad no son tradiciones de una comunidad justa y no tienen por qué defenderse: el multiculturalismo es posible porque la dignidad se encuentra por encima de la política, pero también de la cultura.

\section{Antecedentes del derecho a la participación política de la mujer y la mujer indígena}

Hace apenas unas décadas, no se tomaba a la mujer como persona con autonomía, sino que se le percibía como aquella que debía subordinarse al hombre; mucho menos se hablaba históricamente de ella, pero en la actualidad es más que una moda. Hoy se enfatiza su rol en la sociedad, pasó de ser ama de casa a mujer trabajadora y mujer política que forma parte de las instituciones transformadas acorde con sus necesidades.

El punto de partida para el reconocimiento de la mujer como partícipe de la vida política del país es su derecho al voto, este es otorgado siempre a los ciudadanos: cualquiera que no sea ciudadano, no cuenta con la plena protección del Estado ni con plena capacidad de ejercicio, especialmente tratándose de derechos políticos ${ }^{6}$.

6 "Son derechos del ciudadano: I. Votar en las elecciones populares; II. Poder ser votado para todos los cargos de elección popular, teniendo las calidades que establezca la ley. El derecho de solicitar el registro de candidatos ante la autoridad electoral corresponde a los partidos políticos, así como a los ciudadanos que soliciten su registro de manera independiente y cumplan con los requisitos, condiciones y términos que determine la legislación (reformada mediante decreto publicado en el diario oficial de la federación el 9 de agosto de 2012); III. Asociarse individual y libremente para tomar parte en forma pacífica en los asuntos políticos del país
Aunque en los estados de Chiapas, Tabasco y Yucatán desde 1916 las mujeres además de votar pueden postularse a cargos públicos (Tapia, 2011), fue en el año 1947 que se estableció el derecho generalizado al voto de la mujer en México (CPEUM, art. 8) y es a partir de la participación de la mujer en las elecciones que se reconoce en cierto sentido su ciudadanía.

Chiapas y Yucatán son dos de los estados que cuentan con mayor número de habitantes indígenas (Inegi, 2015), este dato muestra que la mujer es más reconocida en términos de equidad política (para el sufragio) por razón de las propias costumbres y que no en todas las comunidades indígenas impera la desigualdad de género en los mismos grados y formas.

Para el año de 1953, se realiza la reforma a los artículos 34 y 115, fracción I constitucionales, considerando entre otros motivos,

[...] que la mujer mexicana, generosa y desinteresadamente ha presentado su valiosa aportación a las causas más nobles, compartiendo peligros y responsabilidades con el hombre, alentándolo en sus empresas e inculcando en sus hijos los principios morales que han sido un firme sostén de la familia mexicana (Diario de los Debates de la H. Cámara de Diputados, 1953).

El texto resalta que, para los legisladores, la mujer con sus acciones ya había demostrado a la sociedad, hasta esos momentos, que podía poner en marcha su capacidad de ejercicio

(reformada mediante decreto publicado en el diario oficial de la federación el 22 de agosto de 1996); IV. Tomar las armas en el ejército o guardia nacional, para la defensa de la república y de sus instituciones, en los términos que prescriben las leyes (reformada mediante decreto publicado en el diario oficial de la federación el 9 de agosto de 2012); V. Ejercer en toda clase de negocios el derecho de petición; VI. Poder ser nombrado para cualquier empleo o comisión del servicio público, teniendo las calidades que establezca la ley (adicionada mediante decreto publicado en el diario oficial de la federación el 9 de agosto de 2012)" (Constitución Política de los Estados Unidos Mexicanos, DOF, 9 de agosto de 2012, artículo 35). 
con las virtudes propias de su género, pero con el mismo grado de responsabilidad y ética del hombre. En ese mismo sentido, ya no se enunciaba a "los varones con modo honesto de vivir", sino hombres y mujeres mexicanos bajo los requisitos de la Constitución.

A pesar de los avances, las ideas machistas continuaron considerando a la mujer inferior y todavía tuvieron que pasar más años para que incrementara su participación no solo en las votaciones, sino en cargos políticos. Entre las razones que demuestran que los prejuicios no ven idónea a la mujer en la política, existe una muestra realizada en 1993 donde el 62,2\% de los encuestados consideró que "lo mejor que puede hacer una mujer es ocuparse de su casa" (Duarte, 2004, p. 119); por fortuna esta tendencia se ha desvanecido y para el 2002 ya solo un $17 \%$ creyó que la mujer debe ser ama de casa.

Este muestreo no se refiere propiamente a una pregunta enfocada en la participación política, sino social, pero ambos tipos de participación se retroalimentan y no se puede dejar de lado que la percepción de género refleja su influencia en el derecho electoral.

El 15 de agosto de 1990 se crea el Código Federal de Instituciones y Procedimientos Electoralesy a raíz del mismo, nace el Instituto Federal Electoral (IFE); ya que desde 1946, la llamada Comisión Federal de Vigilancia Electoral se conformaba por el secretario de Gobernación, un miembro del gabinete, un diputado, un senador y dos representantes de los partidos políticos de mayor relevancia (Reglamento, 1946); es evidente que no se contemplaba ni siquiera la pluralidad de partidos, mucho menos la posibilidad de presentar candidaturas independientes o algún artículo especial referido a las mujeres o a las comunidades indígenas.

Por ello, los avances de 1990 para contribuir de forma indirecta a la participación política fueron significativos: solo hasta entonces, se prevé la instalación de un sistema electoral con un padrón actualizado de votantes (Código Federal de Instituciones y Procedimientos Electorales, 1992) que pudiera dar certeza y confiabilidad a un método de votación libre y secreto. Además, fue un sistema que permitió por primera vez la transparencia sobre la cantidad de votantes y los estudios estadísticos sobre las características de los mismos como: sus edades, sexo y domicilios reales (que pudieran dar cuenta de las variaciones de votación en virtud de otras circunstancias sociales) y en este caso, el arrojar también datos sobre pertenencia a grupos indígenas que participaban o no en las elecciones.

El 28 de febrero de 1992 se reforma el artículo $4^{\circ}$ constitucional que reconoce el multiculturalismo o desarrollo de la cultura, pero por sí mismo, carecía de fuerza; era urgente que los demás instrumentos jurídicos tuviesen la armonía necesaria para garantizar el respeto de las diferentes culturas, no pasaría mucho tiempo para que se diera la primera llamada de alerta.

En 1994 se vivió una experiencia histórica, inesperada para el gobierno y que con la rebelión del Ejército Zapatista de Liberación Nacional (EZLN), demostró la relación entre la escasez de medios para la subsistencia y la búsqueda de la soberanía ${ }^{7}$. Independiente de las críticas a dicho acontecimiento, uno de los aportes más fuertes que realizó el EZLN al multiculturalismo, fue la búsqueda del derecho a la autodeterminación criticando que no se prevén facultades o formas para que el pueblo pueda adaptar sus institu-

\footnotetext{
"La soberanía nacional reside esencial y originalmente en el pueblo. Todo poder público dimana del pueblo y se instituye para beneficio de este. El pueblo tiene en todo tiempo el inalienable derecho de alterar o modificar la forma de su gobierno" (Constitución Política de los Estados Unidos Mexicanos, DOF, 05-02-1917, artículo 39). "Los dictadores están aplicando una guerra genocida no declarada contra nuestros pueblos desde hace muchos años, por lo que pedimos tu participación decidida apoyando este plan del pueblo mexicano que lucha por trabajo, tierra, techo, alimentación, salud, educación, independencia, libertad, democracia, justicia y paz. Declaramos que no dejaremos de pelear hasta lograr el cumplimiento de estas demandas básicas de nuestro pueblo formando un gobierno de nuestro país libre y democrático" (Primera Declaración de la Selva, Comandancia General del EZLN, 1993).
} 
ciones a las necesidades de sus gobernados y que este grupo plasmó en una serie de leyes revolucionarias, entre las que destacan la Ley de Derechos y Obligaciones de los Pueblos en Lucha (Declaración de la Selva Lacandona) y la Ley Revolucionaria de Mujeres que establecía el respeto e igualdad de las mismas en los ámbitos político, social y económico. Así el EZLN también rechazó que las elecciones tuvieran que cerrarse específicamente con la técnica de partidos políticos cuando solicitaron

Que reforme la ley electoral en términos que garanticen: limpieza, credibilidad, equidad, participación ciudadana no partidaria y no gubernamental, reconocimiento de todas las fuerzas políticas nacionales, regionales o locales, y que convoque a nuevas elecciones generales en la federación (Segunda Declaración de la Selva, Comandancia General del EZLN, 1994).

Con la intención de reforzar el consenso de las propuestas del EZLN, el 27 de agosto de 1995, la organización no gubernamental Alianza Cívi$\mathrm{ca}^{8}$ por invitación del EZLN, organiza consulta nacional por la paz y la democracia (Centro de Documentación sobre Zapatismo, 2013) donde se preguntó a los mexicanos si era necesario hacer una reforma política para garantizar la democracia, y aunque la pregunta es vaga en cuanto las formas (cómo debiera ser dicha reforma) un 95,37 \% respondió que sí. Cabe resaltar que al día siguiente de la consulta, se dieron a conocer los resultados, lo cual lleva a pensar que dicho estudio es falso, pero invita a la gente a reflexionar sobre sus derechos políticos.

En 1996, a raíz de las propias necesidades del sistema electoral, se crea un marco de obligaciones mediante el Manual de organización y procedimientos de la Fiscalía Especializada para la Atención de Delitos Electorales que hasta la

8 Dicha organización había surgido en 1994 como un movimiento nacional y ciudadano, con presencia en todos los estados de la República. (Actualmente impulsa un programa de Transparencia y Rendición de Cuentas para una Democracia con Resultados para la Gente). fecha sigue vigente. Antes de la formación de este organismo, no se contemplaban los fraudes electorales como delitos. "Una pretensión del sistema electoral mexicano de la década de los ochenta, era erradicar conductas fraudulentas, pero sobre todo escandalosas con credenciales de elector que no correspondían al ciudadano y a la alteración de las actas electorales" (Díaz, 2013, p. 46), lo que quizá nadie se imaginó hasta esos momentos, es que las denuncias actuales además de relacionarse con delitos para generar falsos votos, demandarían la inclusión.

Durante los años subsecuentes, las candidaturas independientes fueron un tema de discusión que muchos se plantearon como forma de garantizar la democracia y son un claro antecedente de las acciones tendientes al libre ejercicio de los derechos políticos y el multiculturalismo.

El 13 de septiembre de 2007, se celebra la Declaración de las Naciones Unidas sobre los Derechos de los Pueblos Indígenas, de la cual México es parte, y que entre otros motivos, se genera:

Reconociendo la urgente necesidad de respetar y promover los derechos intrínsecos de los pueblos indígenas, que derivan de sus estructuras políticas, económicas y sociales y de sus culturas, de sus tradiciones espirituales, de su historia y de su filosofía, especialmente los derechos a sus tierras, territorios y recursos (Declaración de las Naciones Unidas sobre los Derechos de los Pueblos Indígenas, 2007).

Con esto se resalta, que los derechos políticos no están separados de la parte empírica, ya que los indígenas, entre otros rasgos, se distinguen por el arraigado apego a sus tierras ancestrales y perciben los recursos del medioambiente como parte de su patrimonio común; mismo que también ha suscitado innumerables controversias históricas por despojos, siendo responsables las empresas mineras ${ }^{9}$, la privación de su derecho

9 Por señalar uno de tantos ejemplos: durante cinco años, de 1885 a 1890, los yaquis de Sonora estuvieron en guerra con una empresa minera hasta que se les envió 
al agua ${ }^{10}$, empresas que talan árboles (Aragón, 2013), entre otras, que conllevan la perpetua desconfianza de los indígenas en el sistema nacional y las ideologías capitalistas que pretenden pasar por alto el derecho al desarrollo de los indígenas a través del medioambiente (Declaración de las Naciones Unidas sobre el Derecho al Desarrollo, 1986). De ahí que también la Asamblea se manifestó en la Declaración (1986).

Convencida de que si los pueblos indígenas controlan los acontecimientos que los afecten a ellos y a sus tierras, territorios y recursos podrán mantener y reforzar sus instituciones, culturas y tradiciones y promover su desarrollo de acuerdo con sus aspiraciones y necesidades.

Más relevante aún, es que los principios por los cuales se crea esta Declaración son los mismos que como sociedad mexicana, proclamamos como parte del discurso social para la consecución de la soberanía nacional e internacional, pero olvidando que ellos también forman parte de la comunidad: "los principios de la justicia, la democracia, el respeto de los derechos humanos, la no discriminación y la buena fe" (Naciones Unidas, 2007).

Como se puede ver, la Declaración de las Naciones Unidas sobre los Derechos de los Pueblos Indígenas, en vez de legislar de manera aislada, propone principios morales que en nuestras contradicciones internas como nación decidimos ignorar. A pesar de los parámetros de interpretación que proporcionó dicho instrumento fueron necesarios muchos cambios en la legislación general para llegar al reconocimiento real del multiculturalismo y el respeto de las diferentes culturas.

En el 2008, se estableció que la sola organización de ciudadanos puede formar partidos y además se implantó la igualdad de oportunidades entre hombres y mujeres (Código Federal de Institu-

en calidad de esclavos a Oaxaca (Vázquez, 2004).

10 Por ejemplo: durante la revolución comunista en el estado de Hidalgo (Díaz, 2002). ciones y Procedimientos Electorales, 2008). Estos dos reconocimientos constitucionales propiciaron que en los años subsiguientes se generara la jurisprudencia que hoy nos permite interpretar ambas vertientes dentro de la gama de argumentos a favor de los derechos políticos de los pueblos y comunidades indígenas. Así mismo, se han reflejado cambios positivos en la práctica de la igualdad, por ejemplo:

[...] mientras en la elección federal de 2009, (primera elección federal en la que se aplicó la cuota de género 60/40), el número de mujeres ascendió a 27.6\% (LXI Legislatura) en la Cámara de Diputados, para 2012 (LXII Legislatura), el número de diputadas se incrementaría de manera importante a un $36.8 \%$ (184 diputadas), mientras que el número de senadoras ascendería a un 34.3 $\%$ (44 senadoras) (Medina, 2010, p. 14).

Lo anterior quiere decir que no solo se promueven las candidaturas políticas de la mujer, sino que estas se observan en las ideas sociales que indican cada vez más que el hombre no es el único que cuenta con el perfil necesario para legislar.

El 10 de junio de 2011 se llevó a cabo la reforma constitucional en derechos humanos en donde México reconoce la obligatoriedad de los tratados internacionales de los mismos:

En los Estados Unidos Mexicanos todas las personas gozarán de los derechos humanos reconocidos en esta Constitución y en los tratados internacionales de los que el Estado mexicano sea parte, así como de las garantías para su protección, cuyo ejercicio no podrá restringirse ni suspenderse, salvo en los casos y bajo las condiciones que esta Constitución establece (Constitución Política de los Estados Unidos Mexicanos, 1917, p. 1).

Esto otorga fuerza a los documentos internacionales en materia de derechos de los pueblos y comunidades indígenas que con anterioridad 
no se aplicaron, así como también, hace que toda la legislación deba adaptarse para estar en armonía con lo dispuesto por la Constitución.

Por otro lado, resolver sobre cuestiones de los derechos políticos de estas comunidades, implica conocer sus costumbres, ya que, en su caso, no solo se debe considerar que no se sujetan a los sistemas de partidos, sino que se deben respetar entre sus usos y tradiciones, el autogobierno mediante una serie de cargos particulares que varían de una comunidad a otra (Singer, 2013).

Entre las sentencias más importantes respecto de la libre determinación de los pueblos y comunidades indígenas, se destaca el caso del municipio de Cherán en Michoacán (Suprema Corte de Justicia de la Nación, 2014) así mismo, sobresale la tesis aún no publicada número XLI/2015 ("Juicio para la protección de los derechos político-electorales del ciudadano", 2015) que enuncia la obligación de los partidos políticos de promover la participación democrática de los indígenas.

Quizá en los próximos años, la inclusión de indígenas en las fórmulas de los partidos políticos arroje los resultados necesarios para que no solo el hombre, sino la mujer indígena pueda participar más activamente, pues desde hace tiempo en la legislación nacional se contempla a hombres y mujeres en igualdad de circunstancias y no existen argumentos jurídicos ni culturales válidos entre sus integrantes para limitar en ningún aspecto los derechos políticos por cuestiones de género.

\section{E. Próximas metas para el ejercicio eficaz de los derechos políticos de la mujer indígena}

Para fortalecer aún más los cimientos de la plena participación política de las mujeres indígenas y disminuir las controversias, en el 2015 se creó el Protocolo de Actuación para quienes Imparten Justicia en Casos que Involucren Derechos de Personas, Comunidades y Pueblos Indígenas.
Este instrumento contiene derechos políticos y sociales; los derechos políticos se aprecian en el apartado 4, denominado "Derechos de las personas, comunidades y pueblos indígenas", en el que cabe mencionar que se tomaron en consideración las sentencias más relevantes que ha proferido la Suprema Corte de Justicia de la Nación.

Así mismo, con la intención de que los indígenas cuenten con una adecuada protección durante los procesos electorales, se creó la Defensoría Pública Electoral para Pueblos y Comunidades Indígenas del Tribunal Electoral del Poder Judicial de la Federación el 7 de marzo de 2016, para encontrar defensores que sean capaces de comprender sus culturas, incluyendo sus lenguas.

Este año, es el momento justo y necesario para culminar con los cambios que garanticen la democracia multicultural: debemos reconocer que uno de los motivos que arraigaron las conductas discriminatorias, fue que por mucho tiempo no se realizaron las reformas suficientes para garantizar sus derechos políticos, pero también estos pueblos deben admitir que la denominación de comunidad a la que tanto se alude existe porque son y deben ser incluyentes con todos sus miembros, sin olvidar a las mujeres.

Contamos con una Ley General de Instituciones y Procedimientos Electorales (2014), una Ley General de Partidos Políticos (2014) y una Ley General en Materia de Delitos Electorales (2014), entre otros instrumentos para el ejercicio de nuestro derecho lectoral. Ahora bien, la Ley General de Partidos Políticos no resulta útil para las comunidades indígenas, por eso se ha requerido analizar:

1. Los elementos comunes por los cuales se regulan los pueblos y comunidades indígenas;

2. Los organismos particulares que integran el cuerpo político de cada una de ellas y en especial;

3. Las formas para generar la igualdad de género. 
Sin embargo, no es una tarea fácil porque como se mencionó, aun entre grupos de la propia etnia existen costumbres de organización muy diferentes, no se pueden estandarizar en un código tan explícito y general.

La antropología jurídica realiza sus investigaciones a partir de un método llamado etnografía, el cual consiste en la observación directa del problema. Los antropólogos llegan a las comunidades y revisan cómo se desarrollan las formas jurídicas en los sistemas normativos indígenas, usos y costumbres (Tribunal Electoral del Poder Judicial de la Federación, 2016, p. 14).

A esto se suma el hecho de que su fuente de derecho son las costumbres que reflejan sus principios sociales y que no encontramos en un texto escrito (Aragón, 2013, p. 39). Los mayores recursos para interpretar correctamente sus necesidades hasta ahora, son las directrices internacionales de derechos humanos que protegen la vida comunitaria. Actualmente no existe un código nacional en materia electoral indígena.

La Ley de la Comisión Nacional para el Desarrollo de los Pueblos Indígenas (2003) es el instrumento que establece los órganos y procedimientos a través de los cuales deben realizarse las consultas a los pueblos y comunidades indígenas, no obstante, desde antes de ejecutarse, ya se criticaba que pasó por alto una situación muy importante: "Uno de los inconvenientes de esta iniciativa es que evade el problema de consultar a los pueblos 'a través de sus instituciones representativas' como mandata el Convenio 169 de la OIT" (Bermejillo, 2005, p. 78).

Hace unos días, el diputado Christian Joaquín Sánchez Sánchez sugirió "cambiar la Ley de la Comisión Nacional para el Desarrollo de los Pueblos y Comunidades Indígenas, para crear un padrón nacional que sirva como herramienta a fin de diseñar e instrumentar programas y políticas más eficaces"11.

11 En sesión de la H. Cámara de Diputados. Tipo de
Menos compleja, pero no sencilla, es la idea de instalar defensores de los derechos políticos de los pueblos y comunidades indígenas, puesto que van a tener que conocer de cultura indígena y del sistema político nacional; porque la finalidad no es solo que las comunidades ejerzan sus derechos en el plano local, sino que se integren al ámbito nacional.

Una formación jurídica puramente legalista ignora que existen puntos comunes y puntos substanciales diversos, pero el conocimiento en derechos humanos nos permite asimilar el multiculturalismo y la flexibilidad que asegure que todos puedan llegar a sentirse representados; en virtud de ello, tiene argumento la creación del Protocolo de Actuación para quienes Imparten Justicia en Casos que Involucren Derechos de Personas, Comunidades y Pueblos Indígenas, dado que no es un código, sino una serie de principios basados en la interpretación de los compromisos históricos de México y las circunstancias suscitadas en el campo jurídico que ha permitido interpretar las necesidades más primordiales de una población representativa del país.

Todo apunta a mayores posibilidades para la igualdad política de las mujeres indígenas, aunque hay cuestiones pendientes. Los indígenas no creen en el sistema político y jurídico porque sus derechos sociales no incluyen hasta ahora, ni siquiera el reconocimiento práctico y solidario para la protección y aseguramiento de sus necesidades básicas (Coneval, 2014). Hay suficientes instrumentos en materia de derecho indígena, pero sus efectos en la práctica son más bien insuficientes para garantizar oportunidades y nivel de vida en todos los aspectos.

Hay que reconocer que la democracia rebasa el ámbito electoral, netamente político. Es un proceso a la vez social y cultural, en todos los ámbitos de la vida social: familia,

evento: Participación en tribuna. 30 de marzo de 2016. Disponible en: http://www.canaldelcongreso.gob.mx/ vod/reproducir/0_0pnby5a0/Diputado_Christian_Joaquin_Sanchez_Sanchez._PRI 
comunidad, empresa, sindicato, partido político, organizaciones de la sociedad civil, medios de comunicación (Stavenhagen, 2007, p. 27).

El diálogo es lo único que en verdad fortalece la democracia, puesto que la forma de gobierno demócrata, es aquella que se explica de acuerdo con su mecanismo para la inclusión y participación y no una manera de hacer política por medio de partidos, ni el derecho de asistir a una casilla a depositar un voto: dar una papeleta de voto a una persona que va a morir de hambre es seguramente deshonesto.

Si llegamos a aplicar los derechos humanos en su aspecto político desde su auténtica finalidad, como principios interrelacionados, indivisibles y universales (Declaración Universal de los Derechos Humanos, 1948), ya no será menester la reapertura de los Acuerdos de San Andrés que en 2003, recomendó abrir el relator sobre los derechos humanos de los indígenas, así como las movilizaciones de cualesquiera de otros grupos indígenas; pero además, la inclusión garantiza que nadie (no solo los indígenas) sea discriminado por el sistema, porque aunque en este trabajo venimos hablando de estos grupos, la raíz de la discriminación es la misma.

Por último, queda pendiente la reducción de los índices de machismo, tanto en el ámbito nacional como regional y local y en todos los actores de la sociedad. Quizá no podemos comprobar que tenga completa razón Víctor Muñoz (2007, p. 112) cuando afirma que: "La relación patriarcal entre hombres y mujeres es la más antigua forma de desigualdad y el primer modelo de discriminación y sumisión del que tenemos noticia", pero lo cierto es que en las sociedades occidentales entre las que está México, sí hemos vivido relaciones de patriarcado con una marcada desigualdad de género, que al arraigarse en el centro de las sociedades, es lo que más impide eliminar la violencia contra la mujer.

En la época actual, se redescubre que las actitudes discriminatorias del pasado, complican mucho más la labor de los derechos humanos, porque el enorgullecimiento de ser individuos aislados, en este caso, principalmente de los grupos indígenas, el conocimiento insuficiente de la historia política de estas comunidades, la decisión de apartarse y vivir en rincones sociales muy diferentes $y$, sobre todo, la falta de interés por aprender sus lenguas $y$ en su lugar, querer cada vez más entender idiomas extranjeros; hoy nos lleva a una tarea que requiere mucho más esfuerzo.

\section{Conclusión}

Utilizamos los términos Latinoamérica, Estadonación, Estado, municipio, pueblo, etc. y nos acostumbramos a distinguirlos con base en las facultades (jurisdicción); pero nos resulta difícil a quienes vivimos inmersos en el sistema de partidos y a los grupos indígenas, acostumbrarnos a la unificación multicultural que no tiene tanto que ver con el territorio como separatista o incluyente, sino con la diversidad que impera sin distinción de regiones. Sea grande o pequeña la dimensión, no se pueden cambiar los criterios y formas de pensamiento por encima de los tradicionales, pero incluso, hasta nuestro sistema político resalta las diferentes ideologías de nuestras condiciones particulares; los indígenas, guardan como característica sus ideales comunes que también conforman política, aunque se distinga una comunidad de otra.

El obstáculo a la participación política de las mujeres indígenas es tanto normativo como social, pues al permitirles a los pueblos y comunidades indígenas la autodeterminación, el Estado mexicano está dejando de proteger legalmente a sus mujeres, ya que en la mayoría de estos, ellas siguen sin gozar de muchos de sus derechos, como el político-electoral; la discriminación social es mucho más notoria al ser de conocimiento público la posición de subordinación que tiene la mujer ante el hombre en estas comunidades, lo que indudablemente la priva de sus aspiraciones políticas.

Mediante la regulación jurídica y la fuerza de sus leyes, se viene intentando poner fin a esta 
situación: se ha influido para que la mujer se sienta capaz de demandar los daños, que sepa que en verdad se reconoce en lo jurídico su igualdad frente al hombre, que el contexto del derecho, en este caso, sí es diferente del contexto histórico-cultural y que poco a poco la historia y la cultura de la diferenciación de la mujer como el género débil, desaparecerá de nuestras percepciones sociales.

La mujer indígena se ha visto frenada por mucho tiempo porque los derechos electorales en la práctica no se han enfocado lo suficiente en ella, pero eso no significa que las cosas deban seguir así, día a día se logran avances que en el futuro garantizarán el respeto al derecho a la participación política de la mujer indígena no solo jurídica, sino socialmente hablando.

\section{Referencias}

Aragón, O. (2013). El derecho en insurrección. El uso contrahegemónico del derecho en el Movimiento Purépecha de Cherán. Revista de Estudios y Pesquisas sobre las Américas, 7(2), pp.37-69.

Becerra, L. \& Mendoza, M. A. (2007). Participación política de las mujeres en Centroamérica y México. Ciudad de México: Asociación Latinoamericana de Organizaciones de Promoción.

Bermejillo, E. (2005). La ley "de" la senadora Calderón. Consultar a los pueblos: ¿trámite o derecho? Disponible en: www. jornada.unam.mx/ 2005/03/21/oja95consulta.html

Cámara de Diputados H. Congreso de la Unión LXIII Legislatura. (2014). Indispensable que las mujeres indígenas accedan y desempeñen cargos públicos. Boletín 3083, 27 de febrero. Disponible en: http://www5.diputados.gob.mx/index. php/esl/Comunicacion/Boletines/2014/ Febrero/27/3083-Indispensable-que-lasmujeres-indigenas-accedan-y-desempenen-cargos-publicos
Centro de Documentación sobre Zapatismo. (s. f.). La consulta nacional de 1995. Disponible en: www.cedoz.org/site/content.php ?doc $=129$

Consejo Nacional de Evaluación de la Política de Desarrollo Social. (2015). Coneval informa los resultados de la medición de pobreza 2014. Comunicado de Prensa, 005, 23 de julio. Disponible en: www.coneval. gob.mx/SalaPrensa/Documents/Comunicado005_Medicion_pobreza_2014.pdf

Díaz, A. (2002). Historia del agrarismo en México. Ciudad de México: Era.

Díaz, H. (2013). Reflexiones sobre los delitos electorales y la Fepade a partir de la alternancia política (2000-2012). Revista Mexicana de Derecho Electoral, 3, enero-junio, pp.43-68.

Duarte, V. M. (2004). Ciudadanía y cultura política: México, 1993-2001. Ciudad de México: Siglo Veintiuno Editores.

Food and Agriculture Organization of the United Nations. (2004). Las contribuciones de la mujer a la producción agrícola y la seguridad alimentaria: estado actual y perspectivas. Disponible en: www.fao. org/docrep/x0222s/x0222s02.htm

Instituto Nacional de Estadística y Geografía. (2015). Encuesta intercensal 2015. Lenguas indígenas en México y hablantes (de 3 años y más) al 2015. Disponible en: http://cuentame.inegi.org.mx/poblacion/lindigena.aspx?tema $=\mathrm{P}$

Larrosa, M. (2007). Partidos políticos, sistemas electorales y sistemas de partidos. En: G. E. Emmerich y V. Alarcón (coords.). Tratado de ciencia política (pp. 193-214). Ciudad de México: Anthropos.

López, J. \& Pitarch, R. P. (2006). Lugares indígenas de la violencia en Iberoamérica. Ciencias y humanismo. Agencia Española de Cooperación Internacional, Dirección General de Relaciones Culturales y Científicas. 
Medina, A. (2010). La participación política de las mujeres. De las cuotas de género a la paridad. Ciudad de México: Centro de Estudios para el Adelanto de las Mujeres y la Equidad de Género, H. Congreso de la Unión Cámara de Diputados, LXI Legislatura.

Muñoz, V. (2007). Un mar de tiniebla: apuntes para una nueva educación. En: G. Ramírez (coord.). Derechos humanos: justicia. Los derechos humanos en las sociedades contemporáneas (pp. 107123). Monterrey: Diálogos.

Nash, R. (2004). Las relaciones entre el derecho de la vida privada y el derecho a la libertad de información en la jurisprudencia de la Corte Interamericana de Derechos Humanos. Santiago de Chile: Facultad de Derecho, universidad de Chile.

Pequeño, A. (2009). Participación y políticas de mujeres indígenas en América Latina. Quito: Facso.

Pineda, R. (2012). El Congreso Indigenista de Pátzcuaro, 1940, una nueva apertura en la política indigenista de las Américas. Bitácoras de Antropología e Historia de la Antropología en América Latina, julio-diciembre, pp. 10-28.

Singer, M. (2013). Justicia electoral. México, participación y representación indígena. Ciudad de México: Tribunal Electoral del Poder Judicial de la Federación.

Stavenhagen, R. (2007). Los derechos humanos en las Américas: nuevos desafíos. En: G. Ramírez (coord.). Los derechos humanos en las sociedades contemporáneas (pp. 21-38). Monterrey: Fondo Editorial de Nuevo León.

Tapia, F. (2011). Tampoco se trata de ser perfectas: relatos de supervivencia, fuerza y amor. Ciudad de México: Océano.

Tribunal Electoral del Poder Judicial de la Federación. (2016). Las resoluciones del TEPJF respetan el derecho constitucional a la libre determinación. Bárcena. Disponible en: www.trife.gob.mx/noticias-opinion-yeventos/boletin/0/8/2016

Vázquez, D. L. (2004). Historia de México: de la época prehispánica a la actualidad: enseñanza básica. Ciudad de México: Limusa.

\section{Legislación y jurisprudencia}

Código Federal de Instituciones y Procedimientos Electorales. Diario Oficial de la Federación. México. (1992).

Código Federal de Instituciones y Procedimientos Electorales. Diario Oficial de la Federación. México. (2008).

Constitución Política de los Estados Unidos Mexicanos. Diario Oficial de la Federación. México.

Naciones Unidas, Asamblea General "Convención sobre la Eliminación de todas las Formas de Discriminación contra las Mujeres". (1979). 18 de diciembre.

Naciones Unidas, Asamblea General " Convención sobre los Derechos Políticos de la Mujer". (1953). 31 de marzo.

Convenio 169 de la OIT sobre Pueblos Indígenas y Tribales en Países Independientes, Comisión Nacional para el Desarrollo de los Pueblos Indígenas, San José. 27 de junio de 1989 se adoptó en la ciudad de Ginebra, Suiza, durante la Septuagésima Sexta Reunión de la Conferencia General de la Organización Internacional del Trabajo.

Declaración de las Naciones Unidas sobre el Derecho al Desarrollo. (1986). 4 de diciembre.

Naciones Unidas, Asamblea General "Declaración de las Naciones Unidas sobre los Derechos de los Pueblos Indígenas". (2007). 13 de septiembre.

Declaración Universal de los Derechos Humanos, Asamblea General (1948). 10 de diciembre. 
Diario de los Debates de la H. Cámara de Diputados 1916-1994. (1953). Legislatura XLII, año legislativo I, periodo ordinario.

Juicio para la protección de los derechos político-electorales del ciudadano. (2015). SUP-JDC-824/2015. Actores: Romel Giovanny Matus y otro. Responsable: Comisión Jurisdiccional Electoral del Partido Acción Nacional, 8 de abril. Unanimidad de votos en cuanto los puntos resolutivos, con la aclaración de que el magistrado Flavio Galván Rivera no comparte las consideraciones. Ponente: Manuel González Oropeza. Ausente: Pedro Esteban Penagos López. Secretario: Esteban Manuel Chapital Romo.

Ley de la Comisión Nacional para el Desarrollo de los Pueblos Indígenas. Diario Oficial de la Federación. México. (2003).
Ley General de Instituciones y Procedimientos Electorales. Diario Oficial de la Federación. México. (2014). 23 de mayo.

Ley General de Partidos Políticos. (2014). DOF, 23 de mayo.

Ley General en Materia de Delitos Electorales, DOF, 23 de mayo de 2014.

Protocolo de Actuación para quienes Imparten Justicia en Casos que Involucren Derechos de Personas, Comunidades y Pueblos Indígenas. Diario Oficial de la Federación. México, 15 de abril de 2013.

Reglamento de la Comisión Federal de Vigilancia Electoral y de las Comisiones Locales Electorales. Diario Oficial de la Federación. México. (1946). 8 de mayo.

Suprema Corte de Justicia de la Nación. (2014). Tribunal Pleno, Décima Época, Seminario Judicial de la Federación, 17 de octubre. 